\title{
Exploring Cultural Values in Conflict Management: A Qualitative Study of University Heads of Departments
}

\begin{tabular}{|r|l|}
\hline Journal: & Qualitative Research in Organizations and Management \\
\hline Manuscript ID & QROM-06-2020-1953.R3 \\
\hline Manuscript Type: & Original Article \\
\hline Keywords: & $\begin{array}{l}\text { Conflict management, Hofstede's cultural theory, Cultural values, Heads } \\
\text { of department, Nigerian universities, Conflict resolution }\end{array}$ \\
\hline \multicolumn{2}{r}{} \\
\end{tabular}

\section{SCHOLARONE \\ Manuscripts}




\title{
Exploring Cultural Values in Conflict Management: A Qualitative Study of University Heads of Departments
}

\begin{abstract}
Purpose: In seeking to understand the impact of culture on conflict management (CM), extant organisational management research has, for the most part, confined itself to using the onedimensional collectivism/individualism model of Hofstede's cultural theory. The present study extends this knowledge area by adopting the more comprehensive analysis of Hofstede's fourfold dimensional typology_power distance, individualism/collectivism, uncertainty avoidance and masculinity/femininity — as a conceptual lens to investigate how national culture impacts the interpersonal conflict management of those in leadership positions in higher education institutions. Specifically, this article explores the extent to which cultural values influence the conflict management practices of university heads of departments (HODs).
\end{abstract}

Design/methodology/approach: Adopting a qualitative approach, 36 interviews were conducted with heads of different departments across a variety of disciplines in selected Nigerian universities.

Findings: The study's results conceptualise how underlying cultural norms-promoting paternalism, servility and social relations - influence the conflict-handling strategies adopted by university HODs. It consequently emerged from our thematic analysis that in Nigeria, conflict-handling decisions are shaped by status-based dictates, a normative emphasis on communality, masculine hegemony and religious motivation - as opposed to Western cultures, where these benevolent and integrative values play a far smaller role.

Limitation/implications: The study focused on a small group of research subjects. Although the sample is not a sample that enables generalisation, our findings provide theoretical insights into how cultural ascendancy could frame conflict resolutions. This research is especially relevant as it runs in a culture significantly different from the ones that originally were investigated and in which managerial books and mainstream practices emerged and, thus, can contribute to challenge and enhance theory.

Originality/value: The study seeks to advance knowledge of the interface between culture and conflict management in a Sub-Saharan African context where literature is scarce.

Keywords: Conflict management, Conflict resolution, Hofstede's cultural theory, cultural values, heads of department, HODs, Nigerian universities

\section{Introduction}

The diverse ways in which cultures differ in terms of conflict management (CM) practices, especially within the workplace, have been a key area of organisational research interest (Neuliep and Johnson, 2016). While interpersonal conflict is often described as a pervasive and inevitable phenomenon in all human endeavours, a wealth of evidence has revealed that the way people deal with such conflict is largely shaped by their broader cultural orientation (Chen et al., 2018). Broadly, culture is a collective programming of the mind that distinguishes members of one group from another (Hofstede, 1991). Prior studies on cross-cultural CM have revealed the extent to which national values shape CM practices in organisational settings (Zhang et al., 2017). National culture often comprises the languages, beliefs, religions, racial 
identities, behaviours and traditions commonly shared by the population of a sovereign country (Steenkamp, 2001). In any society, the national culture's underlying characteristics are highly presumed to have the potential to model social interactions in the workplace (Gahan \& Abeysekera, 2009). As such, national culture can be so ingrained among people as to shape every sphere of conflict-handling practice (Kim-Jo et al., 2010). This observation serves as the context and impetus for the present article.

This study focuses on exploring how national values inform CM practices among Nigerian university heads of departments (HODs). It is worth noting that national culture, often acquired from childhood, is more deeply rooted in the human mind than organisational culture, which shapes perceptions of job roles and practices within an organisational environment (Ma et al., 2010). Current knowledge about the interface between cultural context and conflict resolution (CR) comes from studies undertaken in Western societies (Hann et al., 2016), while there is a paucity of similar studies on developing countries in Sub-Saharan Africa, where cultural orientations differ from the West. Similarly, there have been cross-cultural studies comparing how context shapes conflict-handling strategies in Western and Asian countries. Examples include studies into cultural CM variations between US and China (e.g. Doucet et al., 2009) and between the US and Mexico (Gomez and Taylor, 2018). Similar research in other nonWestern contexts, such as Nigeria, is scarce.

Remarkably, CR strategies differ significantly between national cultures. For instance, crosscultural studies have frequently found that in individualistic Anglo-American cultures, CM tends to be more overt and competitive, while managers in collectivist East Asian Confucian societies (e.g. Japan, South Korea and Taiwan) prefer to adopt strategies that are more harmonious and compromising (Morris and $\mathrm{Fu}, 2001$ ). To date, cross-cultural studies into different conflict handling methods have consistently restricted themselves to relying heavily on the individualistic/collectivistic construct. This construct, however, represents only one of the four value orientations of Hofstede's landmark theory that conceptualises the different and unique dimensions in which cultures vary. In seeking to expand the knowledge of how culture influences the diverse landscape of CR negotiation - especially given the multiplicity and complexity of cultural dynamics - the present study has taken a more nuanced approach by going beyond the individualistic/collectivistic dichotomy to consider the other cultural typologies as well. While recognising the progress made by existing studies in illustrating the extent to which context informs $\mathrm{CR}$, the fact remains that these studies have chosen to only incorporate one aspect of Hofstede's theory - the individualistic/collectivistic construct - in seeking to portray the complex nature of cultural orientations in different contexts. This raises many unanswered questions. This study seeks to address these questions and broaden the understanding in this area, particularly in the context of a Sub-Saharan African region where studies are hard to find.

In addition, researchers have increasingly adopted quantitative methodologies to examine the nexus between culture and CM constructs (e.g. Saiti, 2015; Gomez and Taylor, 2018). While this method generates statistical analysis that makes findings generalizable, there is a need for qualitative studies that give readers an opportunity to discover rich in-depth narratives (Saunders et al., 2012). Critics argue that Hofstede's adoption of a survey design may not be an accurate methodology for determining and measuring cultural studies, particularly when the variables being examined are culturally sensitive and highly subjective (Morris et al., 2001; Chaisrakeo and Speece, 2004). Furthermore, in the Sub-Saharan African context, the paucity 
of extant research into the impact of national culture on CM practices may mean that empirical testing with preconceived hypotheses_-presumptions based on lived experiences - may be premature.

Therefore, the present, qualitative study focuses on Nigerian cultural characteristics and explores the interpersonal conflict-handling methods of university HODs in that context. Comprised of over 250 ethnic groups, Nigeria is famously one of the most populous black West African country, with an estimated population of over 200 million (Worldometrics, 2020). Its culture is known for its highly collectivistic traditions (Chukwu and Eluko, 2013). As such, there are strong tendencies towards social groups and obligations that may encroach on personal space - as opposed to more individualistic nations, such as the US and the UK, where autonomy, privacy and self-projection are highly prioritised (Jackson, 2004). Institutionalised gender dominance is another feature of the Nigerian society, which has been described as less egalitarian and more patriarchal nation, where men are socialised to become breadwinners and the women are primarily expected to engage in childcare and other domestic activities (Mordi et al., 2013). Other normative features of the Nigerian culture include high respect for the elderly, diverse religious beliefs, and acceptance of gender inequality and status differentials, particularly in organisational settings (Ituma et al., 2011). These cultural values are often perceived as framing interpersonal relations and behaviour in Nigeria (Akanji, 2020).

Sadly, Nigeria is also plagued with a variety of problems due to political instability, a high degree of corruption, economic instability and weak governance (Mordi et al., 2013). Despite these socioeconomic challenges, there has always being a strong emphasis on educational achievement (Ituma et al., 2011). The introduction of Western education into Nigeria led to the development of the country's university system (Garba, 2012). This gave Nigerians the opportunity to earn the requisite university education for labour market entry, both locally and internationally, especially after the country's independence in the 1960s (Iruonagbe et al., 2015). A university system constitutes the highest standard of learning in any country. Spratlen (1995) emphasises that interpersonal conflicts, which are often an inevitable element of personal relationships, are bound to occur among categories of stakeholders within the university community. As a result, it is suggested that in institutions of higher education, proactive leadership styles are required in order to shape constructive approaches to CR (Akanji et al., 2019).

One such prominent university leadership position is that of the HOD, or departmental chair (Stanley and Algert, 2007). Mathias (2006, p. 65) pointed out that 'the head of department occupies a key institutional position, yet the role is a complex and demanding one which is subject to pressures, conflicts and uncertainties'. In Western university workspaces, there have been a few studies that have scrutinised the landscape of higher education and focused on the leadership of departmental heads in their ability to manage interpersonal conflicts (Lumpkin, 2004; Mathias, 2006; Stanley and Algert, 2007). Similar studies in a non-Western context, however, are rare.

Interpersonal conflicts that occur in organisational settings refer to disagreements among individuals in a working relationship arising from divergence of interests and concerns (Baillien et al., 2017). As such, a study of this nature can enlighten both knowledge-seeking academics and HR practitioners on contextual differences in the conflict-handling protocols of an under-researched country outside the West. Drawing on the various facets of Hofstede's 
culture model, this study specifically addresses the following research question: how does national cultural orientation shape the CM styles adopted by university HODs when addressing interpersonal conflicts?

\section{Theoretical framework of study}

Geert Hofstede made a significant contribution to the body of knowledge on the impact of national culture on the values of those living and working in various societies. His landmark study emerged from his large-scale research of employees at IBM Corporation located in forty different countries (Mullins and Christy, 2013). Hofstede's initial line of inquiry distinguished national cultures from one another according to four typologies, or orientations - social, power, uncertainty and gender (Hofstede, 1980). Each of these orientations were found to influence the attitudes, behaviours, values and belief systems of members of the society under study (Hofstede, 2001).

Explaining the fourfold typology in more detail, Hofstede argued that differences in social orientation are the extent to which a given culture is either collectivistic or individualistic. In individualistic cultures, the inherent desire for the supremacy of personal goals and selfprojections takes priority over concerns for a larger group. In collectivistic societies, on the other hand, the need for social relationships takes precedence.

Power was identified by Hofstede in terms of power distance (PD), conceptualised as the extent to which a culture accepts and endorses the uneven distribution of power and status privileges among members. Nations with high PD tend to expect unquestionable obedience and submission towards superiors with acclaimed status and authority. Conversely, in lower PD countries, people expect and accept power relations that are more consultative in nature and recognise equality of rights.

As for the dimension of uncertainty, the uncertainty avoidance index (UAI) describes the extent to which people in a society are not at ease with ambiguity and uncertainty in realties confronting them. For instance, societies with a high UAI strongly rely on formalised policies and procedures in order to alleviate unforeseeable circumstances, while those with a low UAI depend on informal norms and beliefs for most matters (Wekhian, 2015).

Finally, the gender dimension refers to the distribution of values based on gender perceptions in any given culture. According to Hofstede (2001, p. 297), 'masculinity stands for a society in which social gender roles are clearly distinct - men are supposed to be assertive, tough, and focused on material success; women are supposed to be more modest, tender, and concerned with the quality of life'.

These cultural typologies comprise values that include tendencies to prefer certain end states over others (Gardner and Barcella, 2016). Values are perceived as customary and are known as the essential roots influencing social behaviour (Bulley et al., 2017). As such, both national culture and context-specific traditions at a national level potently shape a negotiator's interests and priorities, which are often reflected in their preferred CR strategy (Neuliep and Johnson, 2016). By comparing and contrasting cultures conceptualised by the 'Hofstedian' approach, prior research has utilised the traditional two-dimensional model's five styles (Thomas and Kilmann, 1974) to analyse the types of cultural orientations that people exhibit during dispute resolution. The model is based on one of two dimensions that the conflict handler may prioritise in addressing a conflict situation: assertive behaviours in order to project 'self-image', or 
displays of 'cooperativeness', indicating concern for others. Consequently, these two dimensions are used to define the five typologies, or behavioural descriptions, of specific conflict-handling methods, namely: (1) competing, (2) accommodating, (3) collaborating, (4) compromising, and (5) avoiding.

'Competing', as a style, is characterised by showcasing a domineering attitude channelled towards achieving a 'win-lose' situation, in which the individual is more focused on advancing their own interests at the expense of those of others. This approach is described as assertive and uncooperative. Conversely, an 'accommodating' style is described as unassertive and cooperative, in which an individual relegates personal interest and yields to the concerns of others. 'Collaborating' is recognised as both assertive and cooperative, because it involves attempts to work with others to reach a win-win situation. 'Compromising' is categorised as moderating concerns for both self and others. It requires both assertiveness and cooperativeness. The aim is to proffer concessions when resolving disagreements between parties. 'Avoiding' is considered unassertive and uncooperative, since it can take the form of delaying resolution, sidestepping problems or postponing the conflict settlement to a later time.

One of the most frequently examined areas in relation to national cultural differences relates to how value differences impact the preferred CR modes, using these fivefold styles as an explanatory model (Hofstede, 1980). For instance, it has been found that Asians value social ties, making them endorse subtle accommodating approaches when handling conflicts, unlike Americans, who are considered ardent problem-solvers and adopt a more competitive stance in CM (Gomez and Taylor, 2018).

Drawing on these findings, which link cultural distinctions to different approaches in dispute resolution, there are a sizeable number of studies that predominately focus on the individualistic/collectivistic dimension in exploring contrasting CM styles between Western regions and Asian countries - while neglecting those of other cultures. Given the paucity of research in an African context, this article, and the study on which it is based, aims to explore how Nigeria's cultural characteristics (as outlined above) affect its practices with regard to CR, as compared and contrasted with those of the Western world. The study focuses on informing a wider academic audience on how those values affect $\mathrm{CM}$ in a non-Western context. In doing so, Hofstede's cultural dimensions theory is applied to the phenomenon under study, which is yet to be adequately understood and explained theoretically in the Nigerian context. To address the specific research question, rather than following existing studies and confining itself to analysis based solely on individualistic and collectivistic distinctions, this study seeks to critically engage with all of Hofstede's cultural dimensions.

\section{Methodology}

A qualitative design was adopted for the study's data collection and analysis. This naturalistic method refers to 'any kind of research that produces findings not arrived at by means of statistical procedures or other means of quantification' (Strauss and Corbin, 1990, p. 17). A qualitative approach was considered most suitable for the study because it is an appropriate means of gaining an in-depth understanding of a currently under-researched phenomenon (Cresswell, 2008). Broadly, it involves an interactive process between literature and evidence, helping researchers to understand reality beyond the range of taken-for-granted assumptions about lived experiences (Saunders et al., 2012). Moreover, the paucity of research on the interface between culture and CM in the Nigerian context suggests that testing with pre- 
conceived hypotheses may be premature. Epistemologically, the study draws on a social constructivist tradition, with an emphasis on discovering rich contextual data from people's narratives (Bryman, 2012). Taking this perspective, social reality is portrayed as an 'on-going and dynamic process, constantly reproduced by people acting upon their representation of it' (Fernando, 2012, p. 467). This methodology provides an appropriate framework in which to develop an in-depth understanding of the topic being researched.

Based on the researchers' subjective judgement, a non-probabilistic purposive sampling method was used to recruit 36 participants - 26 males and 10 females - from three Nigerian universities in different academic faculties. All were HODs with a status of senior lecturer or higher. Participants (aged 45 to 75) were solicited through a combination of using existing contacts, referrals, and a snowballing process. Requirements for eligibility were holding a position of HOD with a minimum of ten years of work experience in one's academic field.

In compliance with ethical considerations, formal permission was granted by those in charge of research protocols after the study met the requirements and administrative approval of each of the institutions' standards for research on human subjects. One of the conditions for such approval was that the anonymity of the participants and selected universities would be preserved. In order to do so, the HODs were given pseudonyms, labelled HOD 1, HOD 2, HOD 3 , etc. In addition, the principles of informed consent and voluntary participation were highly prioritised. This included consent forms being presented to the participants at the start of each interview, as well as all interviewees being adequately informed about the purpose of the research.

Due to the very busy nature of the offices of some HODs, we had to relocate to quiet study rooms within the university premises, in other to minimise distractions and safeguard the voice recordings (Saunders et al., 2012). The study researchers who conducted the semi-structured interviews were Nigerian, with similar cultural backgrounds to those of the participants; this helped to alleviate any reticence the interviewees may have felt and encouraged them to fully engage in the sessions. The individual interviews lasted for about 45-65 minutes and were all conducted on site. Data collection lasted for close to four months.

The semi-structured interviews allowed for a pursuit of an in-depth understanding of cultural perspective and $\mathrm{CM}$, with the open-ended questions approach allowing for flexibility in discussions. We asked each HOD a series of open-ended questions framed around the main point of our inquiry. Representative of the questions asked:

- Making references to our broad national culture, how would you, as a HOD, typically describe your CM style?

- From the perspective of our societal values, do you feel that the relative importance of your position as a HOD, or the interests of the conflicting parties, dominates your conflict-handling style, and why?

- As the HOD, do you feel you need to have a perfect answer when addressing interpersonal conflicts among your faculty members, and why?

- Do you feel that your gender shapes your CM style?

To improve the study's credibility and reliability, we chose to use iterative questioning - asking probing questions. The objective of this approach was to elicit credible data, as the researchers constantly returned to issues previously raised by the study participants in order to verify their 
claims by rephrasing questions, with the sole aim of eliminating biases. During the interview process, we observed that three of the participants could not initially relate their management style to cultural connotations - the main aim of the study. To solve this problem, we adopted the approach of engaging in a 'constructed dialogue' (Patton, 1990) by highlighting hypothetical scenarios to which interviewees could relate and asking how they would typically resolve such situations. The approach engaged both us, the researchers, and the interviewees in a process that elicited vivid narratives from participants recalling their lived experiences (Pessoa et al., 2019). As researchers, our epistemological assumptions were influenced by a social constructivist approach, which makes it important to reflexively acknowledge our own positionalities when interpreting the lived experiences of our research subjects (Shaw et al., 2019). Thus, the choice of an interactive style of eliciting answers from interviewees was informed by the national and professional identities of all researchers, who are themselves academics who have served in some leadership capacity in their respective universities.

Given that some aspects of positionality are culturally ascribed, or generally regarded as being fixed - such as nationality, gender and race (Cho and $\mathrm{Yi}, 2019)$ - the fact that researchers and participants shared common cultural, social, and linguistic backgrounds gave us 'lived familiarity' with, and a prior knowledge of, some cultural traits and value orientations shaping the CR behaviours of participants. It also made it easy for us to secure more honest answers and capture all relevant data during transcription, since we were conversant with terminologies that are meaningful in the perspective of participants whose cultural beliefs and behaviours were being studied (Gary and Holmes, 2020).

Prior to data collection, our perceptions as male academics who have held leadership positions (such as module leaders, head of academic planning unit and chair of staff disciplinary committees) were that male academics in managerial positions are more likely to handle conflict in an overt and assertive manner than their female counterparts, who are often expected to be tender and more attuned to showing care and affection to others during CR. Interestingly, however, our study findings (which we cite later in greater detail) revealed how female participants explicitly claimed to employ dogmatic characteristics usually associated with men when resolving conflict situations. These accounts made us better informed of how due to Nigeria's cultural propagation of gender role differentiations, female professionals often intensify their efforts to overcome stereotypes firmly ingrained in the society's heavily patriarchal nature (Akanji et al., 2020). We thus became sympathetic to how women living in an inegalitarian society become more resolute to manage workplace conflicts despite perceived gender role limitations (Adisa et al., 2019).

In addition, frequent debriefing sessions were held among researchers in order to ensure that all the interview protocols had been completely observed so that the collected data would be reliable (Lincoln and Guba, 1985). With the participants' formal permission, all the interviews were audio recorded. All the questions asked (see the samples described earlier) captured the four dimensions of Hofstede's theory as we rigorously explored the study's main research question. Our interview sessions continued until saturation point, the stage at which no new information is discovered during the data collection process and at which further data collection is unlikely to reveal new insights (Strauss and Corbin, 1990). After 36 individual interviews, we determined that data collection could cease and proceeded to the analysis of all material data. 


\section{Data analysis}

We began the data analysis by transcribing the voice recordings. Before analysis, the transcribed interviews were returned to the participants for 'member checking' in order to confirm the accuracy of all related data. Member checking is often mentioned as a validation method for judging good qualitative research (Birt et al., 2016). After all the material data had been confirmed, we undertook the thematic analysis procedure (TAP) due to its flexible, yet grounded, approach. TAP is an inductive method for identifying, analysing and reporting patterns within data and allowing researchers to use a research question as a starting point for identifying themes that can shed light on the area of interest (Braun and Clarke, 2006). TAP involved an analytical process through which the transcribed interviews were fractured and subsequently integrated to form conceptual themes grounded in the data.

Following the data collection process, iterative thematic coding was carried out in stages. We began with a first cycle of coding, which involved identifying the Nigerian cultural characteristics constructed from participants' narratives. This became the first step in organising our data about how values shape CM. We then assigned words or short phrases that symbolically described these cultural attributes. Further analysis of the transcripts generated second-order codes that presented culturally inclined conflict-handling protocols based on participants' claims. Finally, the code categories generated from both the first- and secondorder coding systems were consolidated, given the underlying cognate ideas they represent. In a bid to generate theoretical explanations of the phenomenon under study, the codes were appropriately amalgamated to form conceptual themes, as shown in Table 1.

\section{Insert Table 1 here}

In this final stage, a process of cross-comparison and modification in the overall coding process continued until a consensus was reached by all researchers on what should constitute the main themes of the study. As such, we considered the labelling of the codes representing the themes to be accurate and reflective of the meanings that the participants expressed about their $\mathrm{CM}$ styles and the cultural reasons for adopting such styles.

\section{Results and discussion}

In presenting the findings, illustrative quotations from participants (see Table 1) are used to explain themes emerging from our data analysis. The foregoing quotations, as the primary source of evidence, are written verbatim to aid in storytelling, which provides readers with findings reflecting the participants' experiences and contexts (Cresswell, 2008). In-depth analyses of each thematic area are given below.

\section{Status-based dictates}

Based on our findings shown in Table 1, some HODs explained that they operate from a position of power, rank and superior age (elders are respected in Nigeria), which makes their CM style appear paternalistic in nature. Paternalism is conceptualised as a portrayal of selfinterest and good will (Aycan, 2006). Reflecting on participants' job positions as the interviews progressed, the researchers - who are all Nigerians and share a similar social identity to that of the HODs - could relate to the participants' cultural views. We are aware of how workplace superiors often have an attitude of paternal (or maternal) responsibility towards their subordinates, who remain loyal to their superiors if they feel that they are treating them fairly 
or fulfilling their obligations, as is expected in a reciprocal arrangement (Pellegrini et al., 2010). Consequently, we became interested in understanding how paternal values shape CM modes. Thus, the participants' accounts demonstrate their preference for conflict-handling methods that combine a strong use of authority and a benevolent disposition. This cultural inclination explains the tendency of senior academics holding leadership positions (such as HODs) to show elements of control when handling interpersonal conflicts among members of staff under their leadership. They claimed to manage conflicts using self-asserting behaviour bearing some resemblance to a competing style. The following quotations typify participants' shared views suggesting how paternalistic relationships, through their emphasis on power differentials, shape CM practices:

I really don't entertain unsolicited discretion [...] compliance has to be $100 \%$ my way, and when anyone deviates from the established protocols, leading to a sharp argument among faculty members, I often remind everyone that I am older and the 'boss' here [...] In dealing with departmental misunderstandings, my caring disposition to stop disagreements at all costs should be respected, obliterating conflicts among subordinates (HOD 9).

You know how our society places extreme value on eldership [...] So, I resolve conflicts as an elder and expect total obedience from my subordinates regardless of the fact that I'm a woman, I will always stand my ground. I am decisive when resolving conflicts, because it affirms my control and care for all-even if they don't see it that way. This approach is necessary for making speedy decisions (HOD 10).

These excerpts show that the adoption of a paternalistic conflict-handling style necessitates the use of defined power relations based on position and status. In Nigeria, paternalism is a type of attitude and behaviour based on patriarchy, which represents an ideological construct that considers men to be superior to women (Adisa et al., 2019). Expressions of dominance by some male participants outlined in Table 1 (e.g. 'I believe we men have more self-asserting behaviours to control conflict than females ...') and perceptions of control ('... [I]n return, I expect absolute obedience from all, regardless of gender, since our society demands absolute respect for elders and superiors at work') illustrate the characteristics of a patriarchal society. Interestingly, HOD 10, a woman, claims to demonstrate paternalistic behaviours (possibly to combat gender prejudices) by asserting a dominating resolution style based on eldership rights. Notably, Nigerians are generally class conscious, which explains why they hold certain societal 'titles' in high regard (e.g. eldership, headship) and why those holding such titles emphasise the need to be addressed appropriately (Okeke, 2017). It gives them a feeling of respect and superiority over others, especially when handling conflicts between juniors.

The most influential theoretical explanation of how CR choices are influenced by culture draws on Hofstede's dimensional analysis, which distinguishes how value orientations operate differently in national cultures. For instance, Nigeria is rated high in PD, with a score of $80 \%$ (Hofstede, 1980). Nigerians are known to accept the authority of managers (traditionally respected and called 'bosses') and treat them with respect, honour and servile disposition (Aluko, 2003). Our study suggests that it is this thriving culture that drives the use of benevolence in managing interpersonal conflicts - explaining and validating claims about the willingness of workplace subordinates (or 'subjects') to serve and please their superiors (Akanji et al., 2020). From this perspective, a great deal of attention is drawn to 'self-image' as a leader. In practice, cross-management literature recognises paternalism as a flourishing tradition in the developing economies of Asia and Africa (Chen and Kao, 2009; Jackson, 2016). 
While Hofstede's findings provide valuable insights into the degree to which respect and acceptance of power relations vary, our findings clarify why the unequal distribution of position and power is more tolerated in some non-Western contexts. Our study utilises Hofstede's theory to explain how the positive view of paternalism in Nigeria is linked with the accompanying acceptability of high PD.

A similar national culture of paternalism also exists in East Asian settings, such as Japanese and Chinese organisations, where moral attachment and deference to those with higher ranks shape CR dynamics (Morris and $\mathrm{Fu}, 2001$ ). However, these conflict-handling practices have been perceived negatively in Western contexts, where individualistic and egalitarian values are more pronounced (Gomez and Taylor, 2018). In Western cultures (e.g. the UK and the US), people view interactions within corporate and social groups as occurring between selfindependent individuals; conflicts, arguments, and disagreements are therefore accepted as being natural aspects of social and organisational life (Posthuma et al., 2006). Hence, Western democracies are perceived as political systems that regulate conflicts between competing interests by socialising individuals to stand up for their rights in conflict situations with superior bodies (Gardner and Barcella, 2016).

In addition, Aycan (2006) has argued that the benevolent features of paternalism have been difficult for Western scholars to comprehend. Martinez (2005) raised similar concerns about the predominant use of control and care as signs of paternalistic dispositions being hard for Westerners to digest. Jackson (2016) reiterates that in individualistic societies, where people focus on self-interest and self-acclaimed behaviours, a leader's care and protective inclinations may be perceived as a violation of privacy.

There is thus a sizeable literature on general differences in CM styles between national cultures based on contrasting values (Doucet et al., 2009). According to Gomez and Taylor (2018, p. 36), 'a value is a tendency to prefer certain end-states over others because these end-states are personally or socially preferable'. As such, an important line of inquiry of our study suggests that CR behaviours are firmly framed by cultural values that translate to attitudes about behaviours which may be considered appropriate and acceptable in one society but rejected by another (Kim-Jo et al., 2010).

\section{Normative emphasis on concessions}

Further evidence revealed that some participants claimed to use a traditional compromising style in managing interpersonal conflict. They described being formal and keeping to protocols in an attempt to satisfy each party's concern by creating shared positions. This style seeks to promote mutual obligations by 'shared positions' and a 'give-and-take approach' (see illustrative quotes in Table 1), influencing their emphasis on compromises being made. This approach is drawn from a societal tradition prevalent in Nigeria that promotes the tenets of mutual obligation. In contrast to the greater individuality of the West, Nigerian culture is recognised as advocating harmony and cooperation within groups. Hofstede argues that cultural characteristics of this nature (i.e. collectivism) lead to the interests of the group taking precedence over those of individuals. Our findings suggest that such a compromising style is premised on a value system that prioritises tolerance for its adherents and obliges them to accept concessions as is shown in the excerpts below. 
The relative interests of the conflicting parties dominate my conflict-handling style. I prefer to settle issues between departmental colleagues in such a way that everyone learns to tolerate one another as a family, in compliance with our societal conventions, which places importance on preserving relationships and social integration (HOD 11).

I use a reconciliatory method when resolving interpersonal conflicts among my departmental staff. Since we have been socialised to build strong affiliations that extend beyond the workplace to other non-work-related domains, I call parties together to settle issues amicably [...] I make everyone aware that it is good that we live in harmony as fellow brothers and sisters in the workplace (HOD 12).

The sampled views indicate how behavioural patterns fostering communality shape the chosen conflict-handling method. The quotations show that the need to maintain social harmony and foster interpersonal relationships significantly impacts how these HODs resolve verbal misunderstandings in Nigerian universities. In this context, a major part of the social fabric of Nigeria is its collectivist culture, in which individuals develop social ties and a mutual obligation to support each other's aspirations (Hofstede, 2001). These actions are intended to restore cordial relations - especially when elders are involved-leading to a preference for a concessionary style, as would be expected of a culture that values interdependence (Ma et al., 2010). Nigerians are known to have a fervent respect for authority and a strong desire to build integrated relationships that also include non-work-related social exchanges with their leaders (Ituma et al., 2011). This is in contrast with the Western world, where a substantial amount of international research has accumulated reflecting Americans' preference for a separation between their work and private lives (Cai and Fink, 2002). Furthermore, there is evidence that in Western contexts, organisational relationships are predominantly based on work contracts (Gomez and Taylor, 2018). Nigerians, on the other hand, are collectivists, and they seek to define themselves as members of a social group. They therefore perceive work and private life to be strongly linked. This offers a potential explanation as to why some Nigerian HODs choose a conflict-handling style that is non-confrontational and fosters harmonious relationships, as was expressed by HOD 11 and HOD 12.

\section{Religious motivations}

The remarkable narratives from the participants expressing this theme (see Table 1) suggest dimensions of religiosity, from claims such as '... [T] his is why, as an ingrained tradition, I pray ...' to '... but my faith in God ...'). These sentiments play an important role in the 'relief of anxiety' associated with the uncertainty of settling conflicts satisfactorily. Hofstede argued that cultural dimensions of this nature demonstrate the extent to which members of a culture feel threatened by unknown circumstances and have created definite rules or institutionalised policies in trying to avoid these situations. In exploring the extent of tolerance towards ambiguity in this context, six participants confirmed that their religious beliefs have a profound motivation on their CM practices. As evidenced in Table 1, this reflects how many HODs use religious grounds to justify accepted cultural practices, both in terms of finding understanding and also in providing some level of assurance that they are making the right conflict-handling decisions. Here, our findings suggest that faith in spiritual powers (i.e. divine providence) provides a relief from such uncertainties (Kogan et al., 2013).

Given this theme's (i.e. 'religious observance') informal nature, research conceptualises Nigerians as having an intermediate UAI score, which does not show a clear preference for well-defined policies, written regulatory guidelines, and cravings for predictability and 
certainty in the big issues of life that are found in some cultures in the West (Hofstede et al., 2010). For instance, in countries like France, Germany and Spain, where citizens are very avoidant of uncertainty, it has been found that they are intolerant of ambiguity, leading to a high value being placed on institutionalised policies, government legislation, written schedules and clear answers to problematic human endeavours (Mullins and Christy, 2013). Countries with a high UAI maintain formal protocols and are intolerant of adhering to superstitious ideas or religious sentiments (Hofstede, 2001). As such, further evidence on informality in our study exposed the adoption of avoidance strategies when handling conflicts, as Nigerian culture highlights the propagation of moral values and reciprocal obligatory traditions to member groups (Mordi et al., 2013). HOD 13 narrates:

I don't claim to be all-knowing, so the way I resolve interpersonal conflicts as the head [of department] is by drawing on my faith as a Muslim. I don't allow parties to narrate the root causes of their disagreements, which can result in more heated arguments, especially between academics [...] I sometimes delay settlement [of a conflict] to calm frail nerves and admonish parties to shun feelings of resentment. Since Islam is a religion of peace, I preach peace to warring individuals and remind them of its importance for our collective good.

HOD 14 makes a similar claim:

... [W]hen resolving interpersonal conflicts brought to my attention as the head [of department], I often ask for divine direction, as a Christian, to sort out the really [difficult] ones. I also allow angry parties to cool down and make them aware that conflicts are inescapable in any social organisation. I advocate adherence to our values of maintaining strong human relations, which includes doing good to others, respecting elders and showing virtues of forgiveness in line with our respective religious beliefs.

The foregoing context-based views show how religious beliefs encourage a preference for avoidance when managing conflicts. It signifies how a culture identified as collectivist deals with uncertainties surrounding CR by engaging in some form of passive communication, such as avoidance tactics, in a bid to enforce interpersonal harmony (Meng et al., 2018). The strategy involves behaviour such as sidestepping or delaying conflict interventions. As shown above in the comments of HOD 13, it is argued that avoidance becomes evident when a negotiator is trying to buy time and give angry parties an opportunity to 'calm down' to reduce tension (Ohbuchi and Atsumi, 2010). Furthermore, studies on CM that deal with comparative cultural contexts found that collectivists, in some cases, tend to choose avoidance tactics over the confrontational methods (i.e. a competing and proactive stance) that have popularly been identified with individualistic cultures (Wekhian, 2015).

From our findings, religion (in this context, either Christianity or Islam) is considered a determining factor in the choice of avoidance. According to Haynes (2009, p. 52), 'religion has a strong - perhaps growing - significance as a key source of identity for millions of people, especially in the developing world' such as Nigeria. It shapes every aspect of national life, including politics, government, economics, education, law and social dealings. While religion constitutes an essential part of culture (Azim, 2017), little is known about the interface between religiosity and conflict-handling choices. The present study has clearly found that in societies like Nigeria, where interdependent values significantly impact people's way of life, religious beliefs offer a prominent medium for minimising strife and social misunderstandings by choosing CM styles that can lead to peace and tolerance - regardless of the specific religion or religious background. Our findings resonate with a prior study of Rasmi et al. (2014), where it 
was found that Arab immigrants to Canada, who were identified as collectivists and believed to be a very religious sect, preferred the accommodating, compromising and avoiding styles when dealing with conflicts within their families. It was notably reported that in conflict situations, adults in this community defer to their parents, both as a sign of respect and in order to maintain relational congruence.

Significantly, our findings on religious motivations further underscore the importance of using a qualitative paradigm to discover the richness of context in explaining how CM behaviours are shaped by cultural instincts. Hofstede's dimensional concepts have faced heavy criticism, because a simple quantification of differences between national cultures promotes a largely static view of culture. This runs the risk of ignoring a variety of other contextual factors which, in some non-Western countries, have significant influence on the traditional values (Williamson, 2002), such as religious observance in Nigeria.

\section{Masculine hegemony}

Interestingly, almost all the female participants admitted to handling conflicts using some behaviours (assertive, competitive and domineering) often characteristically associated with men - despite claims of having caring and motherly dispositions (see Table 1). The widespread cultural values indicate a historically rooted, ideologically admitted and psychologically internalised state of male domination in Nigeria (Adisa et al., 2019). Such systemic and generalised beliefs about gender dominance have been found to inform CM instincts, which originate from societal norms framed by gender differentiation and the need to combat associated gender stereotypes. In addition to the quotations presented in Table 1, these findings are supported by additional samples as well:

I don't let being a woman downplay my ability to manage verbal crises among the academic and non-teaching staff members in my department. I boldly demonstrate conflict-handling expertise and aggressively show my capability to control rancour from escalating [...] I purposefully do this to dislodge cultural ideas that female academics in positions of leadership are feeble in managing misunderstandings like their male counterparts (HOD 15).

As a female HOD, I am hesitant at times to display characteristics associated with women, such as emotionality and sensitivity to conflicting parties [...] I don't want to take the chance of being considered a weak head [of department], necessitating my adoption of a dogmatic approach in settling departmental conflicts-just like how a Nigerian man will always want to preside over the affairs of his own home (HOD 16).

These results demonstrate how the ability to controlling conflict is significantly shaped by a culture that systematically reinforces and legitimises the deeply embedded values of social male dominance and female servility, shaping women's behaviours in attempts to manage gender biases (Adisa et al., 2020). Given how the patriarchal nature frames organisational life in Nigeria, our study context, participants spoke about the existence of gender role differences in terms of the ability to manage interpersonal conflicts as well as societal scepticism about women's abilities to carry out managerial tasks often associated with male, rather than female, attributes (described as 'feeble' and 'weak' in our data). These findings are supported by research evidence that strongly suggests that women demonstrate more androgynous values in order to overcome perceptions that good leaders are male and masculine-especially in cultures where distinct gender role expectations are prevalent across all domains of work and life (Kim et al., 2020). Thus, prior studies have found that in extremely patriarchal societies, 
such as those of South Asia and Africa, gender stereotyping is much more prevalent than in many Western countries, where there is much emphasis placed on equal gender opportunities (Adya, 2008).

\section{Conclusion and implications}

\section{Conclusion}

Drawing on Hofstede's famous four-dimensional model of national culture, this article set out to explore the extent to which national culture informs CM styles in an African country. Situated in a national context (Nigeria) that has been neglected in favour of Western-based research, the study focused on contextual milieus that shape the conflict-handling preferences of departmental heads in selected universities. Since CM is a culturally defined phenomenon, it is perceived that conflict handling differs across cultures (Kim-Jo et al., 2010). Thus, in order to provide more research information on $\mathrm{CM}$ behaviours that can inform a wider audience, international CM research focused on evidence from the global South is necessary (Neuliep and Johnson, 2016). Furthermore, studying CR strategies from non-Western cultures can help to challenge, refine and enrich our understanding of CM in different working environments. As such, our study has important theoretical implications.

\section{Theoretical implications}

As a theoretical contribution, we applied Hofstede's culture theory in understanding how culture influences CM. More importantly, we extended our understanding of the theory by using it to systematise and explain empirical data and make sense of the phenomenon under study. Rather than merely following the existing discourse, which explores conflict-handling strategies only through the prism of the individualistic/collectivistic dimension-representing only a single strand of Hofstede's insights - this study utilised the complete fourfold typology, namely: power distance, individualism/collectivism, uncertainty avoidance and masculinity/femininity. Even though the fourfold typology approach is itself only a simplification of the great complexity of cultures and their possible dimensions, we nevertheless believe that it was fruitful as a point of departure from previous studies, enabling a more intricate discussion and analysis of the values and traditions that characterise Nigeria's cultural system, which is believed to influence social interactions and CM.

Our study highlights the theoretical importance of context and demonstrates how the elaborate application of the cultural typology enables us to gain a much greater appreciation and explanation of the phenomenon (Byron and Thatcher, 2016). For instance, it has been frequently documented that in handling conflicts, people in Western individualistic cultures, such as the US and the UK, adopt assertive, direct and confrontational approaches, associated with competing and dominating modes of behaviour, as they value the need for assertiveness and seek to emphasise personal outcomes over social relationships (Gomez and Taylor, 2018). In collectivist societies, on the other hand, CM styles are more indirect and less confrontational, since value is placed on harmonious outcomes (Gardner and Barcella, 2016).

While our findings confirm the cultural effects of collectivism as already established in the literature, further evidence from our study capturing a contextual theme-status-based dictates - conceptualises how some HODs' styles are culturally constructed to show a strong preference for a domineering stance, bearing resemblance to a competing style (projecting concern for 'self') that is often disassociated with collectivists. While a large body of literature 
has focused on the individualist-collectivist dichotomy, which often signifies a clear distinction between conflict-handling styles demonstrated in opposing cultures (e.g. Americans and East Asians), our findings suggest that cultural instincts in CM could frequently deviate from their expected value outcomes based on other peculiarities in value orientation (Okereke et al., 2018). Such peculiarities have been highlighted in our data, evidencing that Nigerian culture is highly rooted in paternalism, deference, servility and immoderate patriarchy, conceptualised as values projecting status and rank due to the thriving high PD perceived as a normalised and dynamically situated social practice. The ways in which problematic social interactions are settled in such societies are not commonly associated with those of some individualistic cultures and organisational contexts in the West. As such, this research is especially relevant, as it was conducted in a culture different from the ones that were originally investigated and in which mainstream managerial literature and practices emerged. This represents a significant contribution to challenging and enhancing the individualistic and collectivistic theoretical propositions.

Further informed by Hofstede's uncertainty avoidance construct, the authors contribute to the literature by explaining the role that religious beliefs play in shaping CM styles. We highlight the cultural significance of legitimising the myth of faith in God as a pathway to: the amelioration of a certain level of ambiguity associated with making incorrect conflict-handling decisions; further propagating moral lessons, and stressing mutual obligatory values necessary for sustaining social cohesion (Chen et al., 2018). As a contribution, we suggest that religion can play an important role in the relief of anxiety linked with CM uncertainties (Kogan et al., 2013). These findings potentially provide a clear conceptual explanation of why Nigeria receives an intermediate categorisation in the UAI, indicating a lack of any clear preference for uncertainty avoidance (Hofstede, 2010). This is understandable given people's attitudes to spiritual belief systems, which frame organisational practices such as CM (in the study context).

Furthermore, we argue that this evidence gives a more nuanced analysis of the reasons for cultural differences in conflict avoidance preferences than that of the restrictive individualistic/collectivistic dimension often used in the cross-cultural management literature to date (Doucet et al., 2009). In addition, our data, which relies on the accounts of female participants in the study, confirms a social dominance orientation (Adisa et al., 2020) that perpetuates masculine hegemony based on a rigid allocation of gender roles, necessitating female HODs to showcase traits associated with men in order to blend into the stereotype of the ideal manager when settling departmental misunderstandings. Unlike Western egalitarian cultures, which prioritise gender equality, the patriarchal structures deeply embedded in all Nigerian systems and institutions confine women who have been socialised in this context to adopt $\mathrm{CM}$ strategies that are potentially at odds with feminine characteristics.

On a final note, this study has its limitations. A key limitation is that it solely explores the accounts of those in leadership positions in the university (i.e. HODs). In order to provide balanced views, future research could consider the perspectives of other colleagues and subordinates (both academics and non-teaching staff) reflecting on how HODs handle departmental conflicts. In order to maximise credibility, dependability and confirmability of the qualitative findings, future studies could also engage in a discourse analysis or constructivist grounded theory that might explore how national culture interfaces with organisational culture; exploring studies of this nature may reveal that departmental heads are 
bricoleurs who may draw on national and organisational ideas to construct explanations for their CM behaviours. Furthermore, to enable generalisation of the findings, future quantitative research involving hypothesis testing with larger sample sizes is imperative. Finally, it would be interesting to engage in cross-cultural $\mathrm{CM}$ studies by collecting data that compares the research context of Nigeria with that of Western cultures.

\section{References}

Adisa, T. A., Abdulraheem, I. and Isiaka, S. B. (2019), "Patriarchal hegemony: Investigating the impact of patriarchy on women's work-life balance", Gender in Management: An International Journal, Vol. 34 Iss: 1, pp. 19-33.

Adisa, T. A., Mordi, C., Simpson R. and Iwowo, V. (2020), "Social Dominance, HyperMasculinity and Career Barriers in Nigeria, Gender, Work and Organization, DOI:10.1111/gwao.12537 (in press).

Adya, M. P. (2008), "Women at work: Differences in IT career experiences and perceptions between South Asian and American women. Human Resource Management”, Vol. 47 No. 3, pp. 601-35.

Akanji, B., Mordi, C., Simpson, R., Adisa, T. and Oruh, S. (2020). Time Biases: Exploring the Work-Life Balance of Single Nigerian Managers and Professionals. Journal of Managerial Psychology, Vol. 35 No. 2, pp. 57-70.

Akanji, B., Mordi, M., Ituma, A., Adisa, T. and Ajonbadi, H. (2019). The Influence of Organisational Culture on Leadership Style in Higher Education Institutions. Personnel Review, Vol. 49 No. 3, pp. 709-732.

Akanji, B., Mordi, C. and Ajonbadi, H, A. (2020), "The experiences of work-life balance, stress, and coping lifestyles of female professionals: Insights from a developing country, Employee Relations, Vol. 42 No. 4, pp. 999-1015.

Aluko, M O. A. (2003), "The impact of culture on organisational performance in selected textile firms in Nigeria”, Nordic Journal of African Studies, Vol. 12 No. 2, pp. 169-179.

Aycan, Z. (2006), "Paternalism: towards conceptual refinement and operationalization", in Kim, U., Yang, K.S. and Hwang, K.K. (Eds), Indigenous and Cultural Psychology: Understanding People in Context, Springer Science, New York, NY, pp. 445-466.

Azim, M. T. (2017), "Interpersonal conflict handling styles: An Islamic perspective”, South Asian Journal of Human Resources Management, Vol. 4 No. 2, pp. 225-234.

Baillien, E., Escartin, J., Gross, C. and Zapf, D. (2017), "Towards a conceptual and empirical differentiation between workplace bullying and interpersonal conflict", European Journal of Work and Organisational Psychology, Vol. 26 Issue 6, pp. 870-881.

Birt, L., Scott, S., Cavers, D., Campbell, C. and Walter, F. (2016), Member checking: A tool to enhance trustworthiness or merely a nod to validation?" Qualitative Health Research, Vol. 26 No. 13, pp. 1802-1811.

Bulley, C. A., Osei-Bonsu, N. and Rasaq, H. A. (2017), “Attributes of leadership effectiveness in West Africa”, AIB Insights, Vol. 17 No. 1, pp. 11-18. 
Braun, V. and Clarke, V. (2006), "Using thematic analysis in psychology', Qualitative Research in Psychology", Vol. 3, No. 2, pp. 77-101.

Bryman, A. (2012), Social research methods. (4th edn), New York: Oxford University Press.

Byron, K. and Thacther, S. M. (2016), "Editors' comments: What I know now that I wish I knew then - Teaching theory and theory building", Academy of Management, Vol. 41, pp. 18 .

Cai, D. A., and Fink, E. L. (2002), "Conflict style differences between individualist and collectivists", Communication Monographs, Vol. 69 No. 3, pp. 67-87.

Chaisrakeo, S. and Speece, M. (2004), Culture, intercultural communication competence, and sales negotiation: a qualitative approach", The Journal of Business \& Industrial Marketing, Vol. 19 No. 4, pp. 267-282.

Chen, N., Chao, M.C.-h., Xie, H. and Tjosvold, D. (2018), "Transforming cross-cultural conflict into collaboration: The integration of western and eastern values", Cross Cultural \& Strategic Management, Vol. 25 No. 1, pp. 70-95.

Chen, H. Y. and Kao, H. S. (2009), "Chinese paternalistic leadership and non-Chinese subordinates' psychological health", The International Journal of Human Resource Management, Vol. 20 No. 12, pp. 2533-2546.

Cho, S. and Yi, Y. (2019), "Intersecting identities and positionality of U.S.-based transnational researchers in second language studies", International Journal of Research \& Methods in Education, Vol. 42 No. 4, pp. 414-427.

Chukwu, B. and Eluko, J. (2013), "Theories in Nigerian business organisation", European Journal of Business and Management, Vol. 5 No. 17, pp. 166-171.

Cresswell, J. W. (2008), Research design, qualitative and mixed methods approaches, Thousand Oaks, CA: Sage.

Doucet, L., Jehn, K. A., Weldon, E., Chen, X. and Wang, Z. (2009), “Cross-cultural differences in conflict management: An inductive study of Chinese and American managers", International Journal of Conflict Management, Vol, 29 No. 4, pp. 355-376.

Fernando, W. D. A. (2012), “A social constructionist perspective of gender stereotyping at work: A case of highly skilled women in Sri Lanka", Gender in Management: An International Journal, Vol. 27 No. 7, pp. 463-481.

Gahan, P. and Abeysekera, L. (2009), "What shapes an individual's work values? An integrated model of the relationship between work values, national culture and self-construal", The International Journal of Human Resource Management, Vol. 20 Issue 1, pp. 126-147.

Garba, S. J. (2012), “The Impact of Colonialism on Nigerian Education and the Need for ELearning Technique for Sustainable Development", Journal of Educational and Social Research, Vol. 2 No. 7, pp. 53-61.

Gardner, R. and Barcella, W. (2016), "The value of forgiveness in western and Arab/Muslim conceptualisations of interstate conflict resolution”, Journal of Peace Psychology, Vol. 22 No. 1, pp. 91-93. 
Gary, A. and Holmes, D. (2020), "Researcher positionality - A consideration of its influence and place in qualitative research - A new researcher guide", International Journal of Education, Vol. 8 No. 4, pp. 1-10.

Gomez, C. and Taylor, K. A. (2018), "Cultural differences in conflict resolution strategies: A US-Mexico comparison”, International Journal of Cross Cultural Management, Vol. 18 No. 1, pp. 33-51.

Hann, D., Nash, D. and Heery, E. (2016), "Workplace conflict resolution in Wales: The unexpected prevalence of alternative dispute resolution", Economic and Industrial Democracy, Vol. 40, Issue 3, pp. 776-802.

Hayness, J. (2009), "Conflict, conflict resolution and peace-building: The role of religion in Mozambique, Nigeria and Cambodia", Commonwealth \& Comparative Politics, Vol. 47 Issue 1, pp. 52-72.

Hofstede, G. (1991), Cultures and Organisations, HarperCollins, London.

Hofstede, G. (2001). Culture's Consequences: Comparing Values, Behaviours, Institutions and Organizations across Nations. Thousand Oaks, CA: Sage.

Hofstede, G. H. (1980), Cultures' Consequences: International differences in work-related values, Beverly Hills, CA: Sage Publication.

Hofstede, G., Hofstede, G. J. and Minkov, M. (2010). Cultures and organizations: Software of the mind (3rd ed.). New York, NY: McGraw-Hill.

Iruonagbe, C. T., Imhonopi, D. and Egharevba, M. E. (2015), "Higher education in Nigeria and the emergence of private universities", International Journal of Education and Research, Vol. 3 No.2, pp. 1-18.

Ituma, A., Simpson, R., Ovadje, F., Cornelius, N. and Mordi, C. (2011), "Four domains of career success: how managers in Nigeria evaluate career outcomes", The International Journal of Human Resource Management, Vol. 22 No. 17, pp. 3638-3660.

Jackson, T. (2004), Management Change in Africa: A Cross Cultural Perspective, Routledge, London.

Jackson, T. (2016), "Paternalistic leadership: the missing link in cross-cultural leadership studies", International Journal of Cross Cultural Management, Vol. 16 No. 1, pp. 3-7.

Kim-Jo, T., Benet-Martínez, V. and Ozer, D. J. (2010), “Culture and interpersonal conflict resolution styles: Role of acculturation”, Journal of Cross-Cultural Psychology, Vol. 41 No. 2, pp. 246-269.

Kim, K. Y., Atwater, L. and Jolly, P. M. (2020), “The vicious cycle of work life: Work effort versus career development effort”, Group \& Organization Management, Vol. 45 Iss: 3, pp. 351 385 .

Kogan, A., Sasaki, J., Zou, C., Kim, H. and Cheng, C. (2013), "Uncertainty avoidance moderates the link between faith and subjective well-being around the world", The Journal of Positive Psychology, Routledge, Vol. 15 No. 4, pp. 1-8. 
Lincoln, Y. and Guba, E. (1985), Naturalistic inquiry, Beverly Hills, CA: Sage

Lumpkin, A. (2004), "Enhancing the effectiveness of department chair", Journal of Physical Education, Recreation \& Dance, Vol. 75 No. 9, pp. 44-48.

Ma, Z., Erkus, A. and Tabak, A. (2010), "Explore the impact of collectivism on conflict management styles: a Turkish study", International Journal of Conflict Management, Vol. 21 No. 2, pp. 169-185.

Mathias, H. (2006), “The role of the university head of department”, Journal of Further and Higher Education, Vol. 15 No. 3, pp. 65-75.

Martinez, P.G. (2005), "Paternalism as a positive form of leadership in the Latin American context: leader benevolence, decision-making control and human resource management practices", in Elvira, M. and Davila, A. (Eds), Managing Human Resources in Latin America: An Agenda for International Leaders, Routledge, Oxford, pp. 75-93.

Meng, Y., Yu, H., Ma, Z. and Yang, Z. (2018), "The impact of young Chinese employees' notions of work on conflict management styles: An explorative study", International Journal of Conflict Management, Vol. 29 No. 3, pp. 306-326.

Mordi, C., Mmieh, F. and Ojo, S. (2013), “An exploratory study of manager's perspective of work life balance in Nigeria: a case analysis of the Nigerian banking sector", Thunderbird International Business Review, Vol. 55 No. 1, pp. 55-75.

Morris, M. W. and Fu, H. (2001), "How does culture influence conflict resolution? A dynamic constructivist analysis”, Social Cognition, Vol. 19 No. 3, pp. 324-349.

Mullins, L. J. and Christy, G. (2013). Management and organisational behaviour, England: Pearson.

Neuliep, J. W. and Johnson, M. (2016), “A cross-cultural comparison of Ecuadorian and United States face, face work, and conflict styles during interpersonal conflict: An application of facenegotiation theory", Journal of International and Intercultural Communication, Vol. 9, Iss: 1, pp. 1-19.

Ohbuchi, K. and Atsumi, E. (2010), “Avoidance brings Japanese employees what they care about in conflict management: Its functionality and "good member" image" Negotiation and Conflict Management Research, Vol. 3 No. 2, pp. 117-129.

Okeke, O. J. (2017), "Nigerian culture: A barrier to the career progression of women in Nigeria”, Global Journal of Human Resource Management, Vol. 5 No. 5, pp. 1-11.

Okereke, C., Vincent, O. and Mordi, C. (2018), 'Determinants of Nigerian managers' environmental attitude: Africa's Ubutu ethics versus global capitalism", Thunderbird International Review, Vol. 10 No. 2, pp. 1-14.

Patton, M. (1990). Qualitative evaluation and research methods, Sage, London.

Pellegrini, E. K., Scandura, T. A. and Jayaraman, V. (2010), “Cross-cultural generalizability of paternalistic leadership: An expansion of leader-member exchange theory", Group \& Organization Management, Vol. 35 No. 4, pp. 391-420. 
Pessoa, A. S. G., Harper, E., Santos, I. S. and da Silva Gracino, M. C. (2019), "Using reflexive interviewing to foster deep understanding of research participants' perspectives", International Journal of Qualitative Methods, Vol. 18, pp. 1-9.

Posthuma, R. A., White III, G. O., Dworkin, J. B., Yanez, O. and Swift, M. S. (2006), "Conflict resolution styles between co-worker in US and Mexican cultures", International Journal of Conflict Management, Vol. 17 No. 3, pp. 49-260.

Rasmi, S., Daly, T. M. and Chuang, S. S. (2014), "Intergenerational conflict management in immigrant Arab Canadian families”, Journal of Cross-Cultural Psychology, Vol. 45 No. 7, pp. 1124-1144.

Saiti, A. (2015), "Conflict in schools, conflict management styles and the role of the school leader: A study of Greek primary school educators", Educational Management \& Leadership, Vol. 43 No. 4, pp. 582-609.

Saunders, M. N. K., Lewis, P. and Thornhill, A. (2012), Research methods for business students (6th edition). Harlow, England: Pearson Education.

Shaw, R. M., Howe, J., Beazer, J. and Carr, T. (2019), "Ethics and positionality in qualitative research with vulnerable and marginal”, Qualitative Research, Vol. 3 No. 1, pp. 1-17.

Spratlen, L. P. (1995) "Interpersonal conflict which includes mistreatment in a university workplace", Violence and Victims, Vol. 10 Iss: 4, pp. 15-26.

Stanley, C. A. and Algert, N. E. (2007), “An exploratory study of the conflict management styles of department heads in a research university setting”, Innovative High Education Journal, Springer Science, Vol. 32, No. 5 pp. 49-65.

Steenkamp, J. (2001), "The role of national culture in international marketing research", International Marketing Review, Vol. 18 No. 1, pp. 30-44.

Strauss, A. and Corbin, J. (1990), Basics of qualitative research: Grounded theory procedures and techniques. Newbury Park, CA: Sage Publications, Inc.

Wekhian, J. A. (2015), “Conflict management styles in the workplace: A study of first generation Arab Muslim immigrants in the United States", International Journal of Business and Management, Vol, 10 No. 11, pp. 24-42.

Williamson, D. (2002), "Forward from a critique of Hofstede's model of national culture", Human Relations, Vol. 55 Issue: 11, pp. 1373-1395.

Worldometers (2020). Nigerian population. Available at www.worldometers.info/worldpopulation/nigeria-population accessed on 27/04/2020.

Zhang, Y., Wei, X. and Zhou, W. (2017), "An asymmetric cross-cultural perspective on the mediating role of conflict management styles in expatriation", International Journal of Conflict Management, Vol. 28 No. 5, pp. 592-616. 


\begin{tabular}{|c|c|c|c|}
\hline Illustrative quotes & $\begin{array}{l}\text { First-order } \\
\text { codes } \\
\text { (Nigerian } \\
\text { characteristics) } \\
\end{array}$ & $\begin{array}{l}\text { Second-order codes } \\
\text { (traditional CM } \\
\text { approaches) }\end{array}$ & $\begin{array}{l}\text { Main themes } \\
\text { (i.e. concepts } \\
\text { emerging from } \\
\text { cognate codes) }\end{array}$ \\
\hline $\begin{array}{l}\text { 'As an Associate Professor, I display value traits that asserts authority with some level of fatherly benevolence when dealing } \\
\text { with conflicting parties. I care about people having good working relationships but also demand everyone to comply with } \\
\text { my directives on issues that are strictly within my prerogative to settle masterfully [...] I believe we men have more self- } \\
\text { asserting behaviours to control conflict than females in this part of the world' (HOD 1). } \\
\\
\text { 'Traditionally, I am stern when handling conflicts given my position as the HOD [...] I feel no obligation to resolve every } \\
\text { single interpersonal issue because of the enormous responsibilities on my shoulders. However, when such matters disturb } \\
\text { me, I scold erring parties as a father corrects his children and in return expect absolute obedience from all, regardless of } \\
\text { gender, since our society demands absolute respect for elders and superiors at work' (HOD 2). }\end{array}$ & $\begin{array}{l}\text { Paternalistic, } \\
\text { status-accruing, } \\
\text { patriarchal, } \\
\text { elderly regard, } \\
\text { values social } \\
\text { hierarchy }\end{array}$ & $\begin{array}{l}\text { Defined power } \\
\text { relations, } \\
\text { authoritative } \\
\text { handling, resolving } \\
\text { issues through } \\
\text { control and care, } \\
\text { assertive and } \\
\text { uncooperative style }\end{array}$ & $\begin{array}{l}\text { Status-based } \\
\text { dictates }\end{array}$ \\
\hline $\begin{array}{l}\text { 'Inasmuch as I feel my role as the HOD demands respect, maintaining peace among departmental members is my main goal } \\
\text { [...] my conflict-handling approach is often geared towards preserving cordial relationships since we relate with ourselves } \\
\text { like family. When I'm settling personality conflicts among lecturers, I tend to formalise shared positions between parties. } \\
\text { One party cannot be } 100 \% \text { right without considerations to others in accordance to our wider traditions ...' (HOD 3). } \\
\text { 'Although I'm the head, I often adopt a give-and-take approach in an attempt to satisfy interest of disputants. Our societal } \\
\text { culture demands preserving social ties by settling quarrels amicably, especially when an older woman like me intervenes } \\
\text { using my wealth of wisdom and experience' (HOD 4). }\end{array}$ & $\begin{array}{l}\text { Prioritises } \\
\text { family ties, } \\
\text { relationships } \\
\text { prevails, } \\
\text { respecting in- } \\
\text { group relations }\end{array}$ & $\begin{array}{l}\text { Reinforcing social } \\
\text { relations, making } \\
\text { concessions, a give- } \\
\text { and-take approach, } \\
\text { assertive and } \\
\text { cooperative style }\end{array}$ & $\begin{array}{l}\text { Normative } \\
\text { emphasis on } \\
\text { communality }\end{array}$ \\
\hline $\begin{array}{l}\text { 'I don't claim to have all the right answers to conflicts [...] this is why as a tradition, I pray and ask God to give me the } \\
\text { wisdom to deal with difficult disagreements that can potentially threaten the peace of my department [...] I'm less formal } \\
\text { and take a relativistic stance to preserve relative harmony of the department, even if conflicting parties are not completely } \\
\text { satisfied' (HOD 5). } \\
\text { 'I may not necessarily have perfect answers that suits opposing parties to a conflict, but my faith in God provides some sorts } \\
\text { of relief from anxiety of making wrong decisions. When confronted with interpersonal conflicts, I'm initially inert but use } \\
\text { the opportunity to teach parties moral lessons about how to live in peace and congruity in line with our cultural values that } \\
\text { propagates social cohesion ...' (HOD 6). }\end{array}$ & $\begin{array}{l}\text { Religious } \\
\text { observance, } \\
\text { esteeming } \\
\text { moral values, }\end{array}$ & $\begin{array}{l}\text { Religious } \\
\text { inclination, less } \\
\text { formalisation, } \\
\text { passive approach, } \\
\text { non-confrontational }\end{array}$ & $\begin{array}{l}\text { Religious } \\
\text { motivation }\end{array}$ \\
\hline $\begin{array}{l}\text { 'Yes it does, because as a woman and mother, I have a more tender and soft disposition to conflict management in general, } \\
\text { but when handling difficult ones especially when men are involved, I become stricter [...] since men sometimes need } \\
\text { firmness to listen to a woman. I energetically display a high level of emphatic and compelling stance for parties to allow } \\
\text { sleeping dogs lie and embrace placidity because our societal culture esteems cordial social relationships...' (HOD 7). } \\
\text { '... [A]lthough I'm a woman, I disapprove of interpersonal conflicts that slows work down [...] So like a man, I use my } \\
\text { position to settle quarrels by dominating conversations and advising parties that conflict is part of life but being civil about } \\
\text { it is what matters [...] I expect everyone to maintain a servile attitude for the collective interests of my department' (HOD } \\
\text { 8). }\end{array}$ & $\begin{array}{l}\text { Androgynous } \\
\text { tradition, } \\
\text { gender } \\
\text { differentiation, } \\
\text { values servility }\end{array}$ & $\begin{array}{l}\text { Domineering style, } \\
\text { projecting } \\
\text { assertiveness, } \\
\text { displaying mannish } \\
\text { behaviours, } \\
\text { controlling }\end{array}$ & $\begin{array}{l}\text { Masculine } \\
\text { hegemony }\end{array}$ \\
\hline
\end{tabular}




\section{Table 1: Qualitative findings, 2020.}

